\title{
Editorial
}

\section{Clío América y su trayectoria en la investigación científica}

\author{
Oscar Humberto García Vargas ${ }^{1}$
}

La Revista Clío América, desde su creación, ha venido trabajando en la divulgación de los aportes investigativos en temas relacionados con las disciplinas y áreas temáticas de la revista, tales como: economía, negocios y empresas, así mismo, sus diferentes publicaciones han tenido trascendencia en las distintas comunidades científicas relacionadas con las áreas de conocimiento que maneja, evidenciado en las diferentes bases de datos a la cual pertenece actualmente, en especial a Econlit y Emerging Sources Citation Index. Creando de esta forma un entorno apropiado para la conexión de pares y autores internacionales que al publicar y arrojar resultados en nuestra revista, la robustecen para lograr una mayor proyección a nivel internacional y un incremento del índice $\mathbf{h}$ como indicador visible de investigaciones destacadas y reconocidas por la comunidad científica.

En este sentido, se permite enumerar algunas de las publicaciones más representativas realizadas por la revista: Arias, Caraballo \& Matos (2012), autores que trabajaron en el turismo de salud, relacionado con el estado actual del mercado global; también se encuentra la de Muñoz, Ditta \& Duarte (2012), quienes hacen referencia a la medición de la volatilidad desde el punto de vista lognormal y montecarlo; de igual forma la publicación resultado de la investigación realizada por Jiménez, Rojas \& Ospina (2013), donde se resalta la importancia del ciclo de caja en la gerencia de la PYME; la de los autores Ureña, Jiménez, Mejía \& Vilarete (2014), que trabaja sobre la cultura innovativa para el desarrollo del capital humano.

Otras publicaciones corresponden a la de los autores: Gómez (2014), la cual versa sobre la ciencia económica; Sanclemente (2015), artículo basado en la responsabilidad social empresarial y por último la de los autores Arias, Jurado \& Pájaro (2016), quienes orientaron su investigación sobre el impacto que tienen los aportes y donaciones en los almacenes de cadena, además de Pabón (2016), donde se presentan las diferentes políticas de adquisición de vivienda a través de los créditos hipotecarios.

Lo anterior no sería posible sin el apoyo de la universidad del Magdalena, institución editora de la revista y sus objetivos alrededor de la internacionalización y publicación de manuscritos realizados por los diferentes investigadores de las ciencias sociales en el mundo.

\section{REFERENCIAS BIBLIOGRÁFICAS}

Arias, F., Caraballo, A., \& Matos, R. (2012). El turismo de salud: Conceptualización, historia, desarrollo y estado actual del mercado global. Clío América, 6(11), 72-98.

Muñoz, A., Ditta, E., \& Duarte, H. (2012). Medición de la volatilidad del igbc y la trm utilizando las metodologías lognormal y montecarlo. Clío América, 6(12), 150-184.

Jiménez, J., Rojas, F., \& Ospina. H. (2013). La importancia del ciclo de caja y cálculo del capital de trabajo en la gerencia PYME, 7(13). Clío América, 7(13), 48-63.

1. Editor - Universidad del Magdalena. Colombia. Email: ogarciav@unimagdalena.edu.co 
Ureña, Y., Jiménez, I., Mejía, A., \& Vilarete, J. (2014). Cultura innovativa: Prospectiva de las condiciones estratégicas para el desarrollo del capital humano. Clío América, 8(16), 195-200.

Gómez, D. (2014). Apuntes desde la ciencia económica ¿el sujeto racional o el sujeto complejo?. Clío América, 8(15), 83-89.

Sanclemente, J. (2015). La responsabilidad social empresarial (RSE) de los pequeños distribuidores minoristas. Clío América, 9(17), 42-56.
Arias, F., Jurado, J., \& Pájaro, J. (2016). Impacto de los programas de aportes y donaciones de almacenes de cadena de Cartagena sobre la imagen y reputación. Clío América, 10(20), XX

Pabón, J. (2016). La política de vivienda y la adjudicación de créditos hipotecarios en la ciudad de Cúcuta. Clío América, 10(20), XX 